\title{
Role of hysteroscopy in management of abnormal uterine bleeding in perimenopausal women
}

\section{Gurcharan Kaur, Priya Agarwal*}

Department of Obstetrics and Gynaecology, Kasturba hospital, Delhi, India

Received: 21 March 2016

Revised: 02 May 2016

Accepted: 05 May 2016

\section{*Correspondence:}

Dr. Priya Agarwal,

E-mail: priyaagarwalmar26@gmail.com

Copyright: (c) the author(s), publisher and licensee Medip Academy. This is an open-access article distributed under the terms of the Creative Commons Attribution Non-Commercial License, which permits unrestricted non-commercial use, distribution, and reproduction in any medium, provided the original work is properly cited.

\section{ABSTRACT}

Background: In perimenopausal women blind endometrial sampling, dilation and curettage (D and C) was the standard treatment. Since hysteroscopy offers complete visualization of entire endometrial cavity. This prospective study was undertaken to evaluate its role. As whole of endometrial cavity examined and target biopsy can be taken from suspected area so that no carcinoma is missed. Thus, study was conducted to evaluate role of hysteroscopy in abnormal uterine bleeding (AUB) in women of perimenopausal age group and to correlate the hysteroscopic findings with that of histopathology and to see complication of hysteroscopy, if any.

Methods: The study was carried out in the department of obstetrics and gynecology at Kasturba hospital, Delhi, India. 162 patients of age group 40-55 years with AUB were included. Any demonstrable pelvic pathology like cancer of cervix, vagina or endometrium and active pelvic inflammatory disease (PID) was set as exclusion criteria. All patients were subjected to hysteroscopy followed by $\mathrm{D}$ and $\mathrm{C}$ and findings of hysteroscopy and histopathology was correlated.

Results: On hysteroscopy endometrium was normal in $49.3 \%$, hyperplastic in $24.6 \%$, atrophic in $10.4 \%$ and suspected carcinoma endometrium in $3.08 \%$. Endometrial polyp and submucous fibroid was seen in $4.9 \%$ cases and $7.4 \%$ cases each. On confirmation by histopathology the findings were: normal endometrium in $55.4 \%$ cases, hyperplastic in $20.3 \%$, atrophic in $9.9 \%$ and carcinoma endometrium in $1.85 \%$. All cases of submucous fibroid and polyp were confirmed on histopathology.

Conclusions: Hysteroscopy increases the accuracy of clinical diagnosis and may serve as an adjunct in the treatment of patients with specific intrauterine pathological conditions causing AUB.

Keywords: Hysteroscopy, Abnormal uterine bleeding, Dilatation and curettage, Negative predictive value, Positive predictive value

\section{INTRODUCTION}

Hysteroscopy is generally a low risk technique that uses the endocervical canal, the natural passageway to gain entry into the intrauterine environment and offers a valuable extension of the gynecologist's armamentarium. It can improve the diagnostic accuracy and can permit better treatment of uterine diseases. Lesions such as polyp, forgotten intrauterine contraceptive device (IUCD) can be treated at the same time. ${ }^{1}$ Use of hysteroscopy in abnormal uterine bleeding is almost replacing blind curettage, as it "sees" and "decides" the cause. This is because the uterine cavity can be observed and the area in question can be biopsied. In fact, it is an eye in the uterus. $^{2}$ The objective of the study was to evaluate the role of hysteroscopy in abnormal uterine bleeding in patients of perimenopausal age group, to establish the corelation of hysteroscopic findings with histopathology and also to see complication of hysteroscopy. 


\section{METHODS}

The study was carried out in the department of obstetrics and gynecology at Kasturba hospital, Delhi, India, after ethical clearance from institutional ethical committee. 162 patients of age group 40-55 years were included, who were admitted with the history of abnormal uterine bleeding; excluding any demonstrable pelvic pathology like cancer of cervix, vagina or endometrium on clinical examination and active pelvic infection. Detailed history, examination and investigations were done. Hysteroscopic examination was done in all patients post-menstrually. Biopsy was taken from suspected area. The patients then underwent dilatation and curettage and endometrium was sent for histopathologic examination. The findings on hysteroscopy and histopathologic examination were correlated. Data were recorded on a predesigned proforma.

\section{Statistical data evaluation}

Statistical analysis was done of data obtained in terms of sensitivity, specificity, positive predictive value and negative predictive value.

\section{RESULTS}

The average age was 46.6 years. The maximum no. of patients was in age group 45-49 years i.e. $44 \%$. The commonest affected patients were para 3 or more $(64 \%)$ and least affected was nulliparous (3\%). $80 \%$ of the patients were pre-menopausal and $22 \%$ were postmenopausal.

Commonest presentation was menorrhagia in $40 \%$ cases followed by postmenopausal bleeding (22\%). Other presentations were polymenorrhea in $7 \%$ cases, menorrhagia with polymenorrhea in $6 \%$ cases, metrorrhagia in 5\% cases, menometrorrhagia in $9 \%$ cases, and continuous benign positional vertigo (BPV) in $11 \%$ cases. Majority of the patients (44\%) had symptoms for more than 1 year, $32 \%$ had symptoms for 6 months to 1 year and $24 \%$ had symptoms for less than 6 months.

$7 \%$ patients were diabetic, $20 \%$ had hypertension, and $4 \%$ patients had both hypertension and diabetes. Thyroid dysfunction was present in $7 \%$ cases. Anaemia was present in 50 patients, out of which, 10 patients had haemoglobin less than $8 \mathrm{gm} \%$ and rest had haemoglobin between 8 to $10 \mathrm{gm} \%$.

Out of 162 patients, $72 \%$ had normal Pap smear, 22\% had inflammatory Pap smear and $6 \%$ had low-grade squamous intraepithelial lesion (LSIL). Out of 162 cases, $76 \%$ had normal uterus and $24 \%$ had enlarged uterus on pelvic ultrasonography. Endometrial polyp was seen in $7 \%$ cases and fibroid was seen in $8 \%$ cases. No case of retained IUCD or free fluid in pouch of douglas (POD) was seen. In majority of cases endometrial thickness was between $4-8 \mathrm{~mm}$ (46\%). In $36 \%$ cases endometrial thickness (ET) was normal. In $12 \%$ cases ET was between $8-12 \mathrm{~mm}$ and in $6 \%$ cases ET was even more than $12 \mathrm{~mm}$ on pelvic ultrasonography.

All the patients underwent diagnostic hysteroscopy followed by dilatation and curettage and hysteroscopic findings were correlated with histopathologic findings.

On hysteroscopy normal endometrium was noted in $49.3 \%$ cases. The most common abnormality was endometrial hyperplasia in $24.6 \%$ patients, followed by endometrial atrophy in $10.4 \%$ patients, and in $3.08 \%$ patient hyperplastic endometrium with suspicious area was noted. Submucous myoma and endometrial polyp was noted in $7.40 \%$ and $4.9 \%$ each respectively. A finding on hysteroscopy is shown in Figure 1.

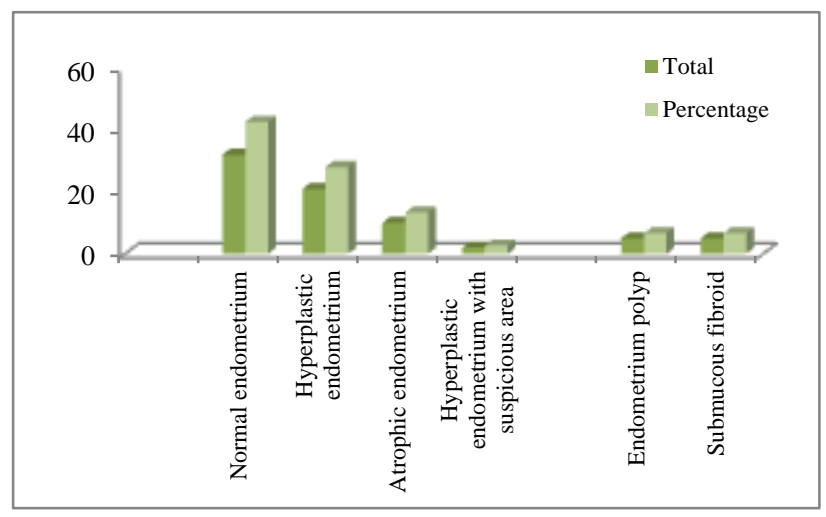

Figure 1: Findings on hysteroscopy.

On histopathology, endometrium was normal in $55.5 \%$ cases, hyperplastic in $20.3 \%$ cases, atrophic in $9.9 \%$ cases and carcinoma endometrium in $1.85 \%$ cases. Endometrial polyp and submucous myoma was seen in $4.9 \%$ and $7.4 \%$ each respectively. A finding on histopathology is shown in figure 2 .

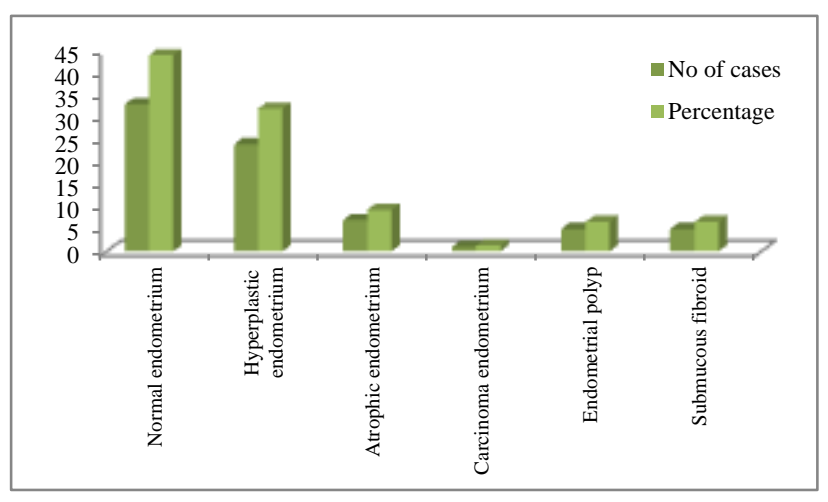

Figure 2: Findings on histopathology.

Endometrium appeared to be normal on hysteroscopy in 80 cases. The same was confirmed by histopathology in 74 cases while the rest 6 cases showed hyperplastic endometrium. Of 40 cases of hyperplastic endometrium on hysteroscopy, only 25 cases were confirmed on 
histopathology and the rest showed normal endometrium. In 17 cases endometrium appeared to be atrophic on hysteroscopy of which 16 cases were confirmed on histopathology and rest 1 cases showed normal endometrium. In 5 cases endometrium was suspected of carcinoma endometrium which was confirmed on histopathology in 3 case and the other 2 cases showed complex hyperplasia with atypia. All cases of endometrial fibroid and polyp were confirmed on histopathology. Diagnostic accuracy of hysteroscopy is shown in Table 1.

After confirming the diagnosis, treatment was given to the patients. In all 12 cases of submucous fibroid hysterectomy was done and diagnosis of fibroid was confirmed on the histopathology of the specimen.

Table 1: Diagnostic accuracy of hysteroscopy.

\begin{tabular}{|c|c|c|c|c|c|}
\hline Hysteroscopy & $\begin{array}{l}\text { Sensitivity } \\
(\%)\end{array}$ & $\begin{array}{l}\text { Specificity } \\
(\%)\end{array}$ & $\begin{array}{l}\text { Positive predictive } \\
\text { value } \\
(\%)\end{array}$ & $\begin{array}{l}\text { Negative predictive } \\
\text { value } \\
(\%)\end{array}$ & $\begin{array}{l}\text { Diagnostic } \\
\text { accuracy } \\
(\%)\end{array}$ \\
\hline Normal endometrium & 82.2 & 91.6 & 92.5 & 80.4 & 86.4 \\
\hline Hyperplastic endometrium & 75.7 & 88.3 & 62.5 & 93.4 & 85.8 \\
\hline Atrophic endometrium & 100.00 & 99.3 & 94.1 & 100.00 & 99.3 \\
\hline E. polyp & 100.00 & 100.00 & 100.00 & 100.00 & 100 \\
\hline Submucous fibroid & 100.00 & 100.00 & 100.00 & 100.00 & 100 \\
\hline $\begin{array}{l}\text { Hyperplastic endometrium } \\
\text { with suspicious area }\end{array}$ & 100.00 & 98.7 & 60.00 & 100.00 & 98.7 \\
\hline
\end{tabular}

One patient had uterine perforation as a complication of hysteroscopy, but the rent was small and did not require any treatment except for monitoring. Rest in all cases no complication was observed. There was no procedure related mortality seen in the study.

\section{DISCUSSION}

Abnormal uterine bleeding is one of the most common condition for which patients seek advice in the gynecology out-patient department. A thorough search for underlying systemic, hormonal, and organic causes should be instituted. The use of blind endometrial sampling alone to evaluate the uterine cavity, by itself, is not a very accurate technique for diagnosing pathologic conditions commonly associated with menorrhagia, such as endometrial polyps, submucous myoma, focal endometrial abnormalities including adenocarcinoma and its precursors. Intrauterine visualization by hysteroscopy for the evaluation of patients with abnormal uterine bleeding (AUB) represents the "gold standard" today. The ability to observe the entire endometrium provides accuracy and precision in sampling. It not only offers a quick, safe and accurate diagnosis, but, also operative hysteroscopy can be performed in the same sitting for removal of polyp, fibroid, intrauterine adhesions, and misplaced IUCD. Haemila FA et al and Reethu et al observed a mean age of 44.8 years and 43.64 years respectively in patients of AUB, which was close to the mean age of 46.6 years, observed in the our study., Majority of the patients $(64 \%)$ were multiparous in our study, and was similar as also reported by Jyotsana et al and Shubhankar D et al where majority of patients to be multiparous (54.7\% and $88.5 \%$ respectively). ${ }^{5,6}$ Fonsena $\mathrm{M}$ et al also observed majority of the patients were multiparous $60 \%{ }^{7}$
Commonest presentation in the study was menorrhagia in $40 \%$ patients, followed by post-menopausal bleeding seen in $22 \%$ patients. A similar finding was observed in the study conducted by Jyotsana et al. where menorrhagia was the commonest presentation seen in $40 \%$ of the patients.

Normal hysteroscopic findings were observed in $49.3 \%$ of the cases which is similar to the study by Sheetal G et al and Dasgupta et al, who observed normal hysteroscopic findings in $50 \%$ and $39.1 \%$ respectively. ${ }^{8,6}$ Close to this value, was in the study by Reethu et al and Jyotsna et al who observed normal hysteroscopic findings in $30 \%$ and $33.3 \%$ of cases, respectively. ${ }^{4,5}$ Most common abnormality detected was hyperplastic endometrium i.e. $24.6 \%$ which was close to that observed in Jyotsana et al and Dasgupta et al which was $22.6 \%$ and $30.6 \%$ respectively but was much lower than observed in Rethu et al study which was $50 \% .^{3,6,4}$ Atrophic endometrium was present in $10.4 \%$ of cases in our study which was close to that observed in Sheetal et al which was $8 \%$ and was much less in Reethu et al study i.e. $2 \%{ }^{8,4}$ Endometrial polyp and submucous fibroid was observed in $4.9 \%$ and $7.40 \%$ cases respectively in our study while in studies of Jyotsana et al, Sheetal et al, Dasgupta et al, and Reethu et al it was $20.3 \%$ and $17 \%$, $9 \%$ and $11 \%, 12.4 \%$ and $18.1 \%$ and $8 \%$ and $10 \%$ respectively. ${ }^{5,8,6,2}$ One important finding in our study was carcinoma endometrium which was suspected in $3.08 \%$ of cases on hysteroscopy and was confirmed in $1.85 \%$ cases on histopthology. It was close to that observed in study by Jyotsana et al and Sheetal $\mathrm{G}$ et al i.e. $1.3 \%$ and $3 \%$ respectively on hysteroscopy while on histopathology similar findings were observed in Jyotsana et al and Sheetal et al i.e. $1.3 \%$ and $2 \%$ respectively. ${ }^{5,8}$ Table 2 
shows the comparison of the accuracy of hysteroscopy in diagnosing abnormal lesions in various studies.

On correlating hysteroscopic finding with histopathology finding sensitivity, specificity, PPV, NPV and accuracy for normal endometrium was $82.2 \%, 91.6 \%, 92.5 \%$, $80.4 \%$ and $86.4 \%$ respectively in our study while in Sheetal et al study it was $78.57 \%, 86.2 \%, 80.4 \%, 84.74 \%$ and $81 \%$ respectively and in Dasgupta at al study it was $69 \%, 100 \%, 100 \%, 71.4 \%, 82.5 \%$ respectively. ${ }^{8,6}$

Table 2: Hysteroscopic findings reported by various authors.

\begin{tabular}{|llllllll|}
\hline Author & Year & Normal & Hyperplastic & Atrophic & Polyp & Sulbmucous fibroid & Carcinoma endometrium \\
\hline Jyotsana et al $^{5}$ & 2004 & $33.33 \%$ & $22.6 \%$ & - & $20.3 \%$ & $17 \%$ & $1.3 \%$ \\
\hline Sheetal G et al & 2009 & $50 \%$ & $18 \%$ & $8 \%$ & $9 \%$ & $11 \%$ & $3 \%$ \\
\hline Dasgupta et al & 2010 & $38.9 \%$ & $30.6 \%$ & - & $12.4 \%$ & $18.1 \%$ & - \\
\hline Reethu et al & 2013 & $30 \%$ & $50 \%$ & $2 \%$ & $8 \%$ & $10 \%$ & - \\
\hline Our study & & $49.3 \%$ & $24.6 \%$ & $10.4 \%$ & $4.9 \%$ & $7.4 \%$ & $3.08 \%$ \\
\hline
\end{tabular}

For hyperplastic endometrium sensitivity, specificity, PPV, NPV and accuracy of hysteroscopy was $75.7 \%$, $88.3 \%, 62.5 \%, 93.4 \%$ and $85.8 \%$ respectively in our study while in Sheetal et $\mathrm{al}^{8}$ study it was $75 \%, 92.5 \%$, $71.4 \%, 93.67 \%$ and $72 \%$ respectively.

Sensitivity, specificity, positive predictive values (PPV), negative predictive values (NPV) and accuracy of hysteroscopy for carcinoma endometrium was $100 \%$, $98.7 \%, 60 \%, 100 \%$ and $98.7 \%$ in our study while in Jyotsana et al study, it was $100 \%$ each. ${ }^{5}$ Sheetal G et al found diagnostic accuracy of hysteroscopy for carcinoma endometrium to be $67 \%$ and sensitivity, specificity, positive predictive value and negative predictive value of hysteroscopy for carcinoma endometrium were 100, 98.97, 66.66 and $100 \%$, respectively. ${ }^{8}$ Hysteroscopy revealed a sensitivity, specificity, positive predictive value and negative predictive value of 100, 49.6, 81 and $100 \%$, respectively, as reported by Pietro Let al. ${ }^{9}$

Sensitivity, specificity, PPV, NPV and accuracy of hysteroscopy for atrophic endometrium was $100 \%$, $99.3 \%, 94.1 \%, 100 \%$ and $99.3 \%$ respectively in our study while in Sheetal $\mathrm{G}$ et al and Reethu et al study it was $100 \%, 96.84 \% 62.5 \%, 100 \%, 63 \%$ respectively and $100 \%$ each. 8,4

For endometrial polyp sensitivity, specificity, PPV, NPV and accuracy was $100 \%$ each in present study which was similar to that observed in Sheetal et al and Reethu et al study that is $100 \%$ each respectively. ${ }^{8,4}$ Similarly for submucous fibroid sensitivity, specificity, PPV, NPV and accuracy of hysteroscopy was $100 \%$ each which was also similar as observed in Sheetal et al and Reethu et al study that is $100 \%$ respectively. ${ }^{8,4}$ Abnormal uterine bleeding which often prevails as an important and common gynecological ailment in the perimenopausal age group is commonly associated with painless menorrhagia. Most of the patients may have normal endometrium but however a significant number have uterine lesions, commonly being hyperplasia. Our study has proved the utility of hysteroscopy in the diagnosis of various endometrial and intrauterine lesions, with high sensitivity, predictive value of a negative test and low false negativity. However specificity may be low and false positive finding may occur, hence biopsy and histological confirmation is required in all cases. Thus hysteroscopy should be used as a first line diagnostic modality in patients complaining of abnormal uterine bleeding.

\section{CONCLUSION}

Hysteroscopy is a valuable, simple, low-risk technique which allows an adequate visualization of the entire uterine cavity. Hysteroscopy increases the accuracy of clinical diagnosis and may serve as an adjunct in the treatment of patients with specific intrauterine pathological conditions. In patients with abnormal uterine bleeding, hysteroscopy provides the possibility of immediate diagnosis and effective treatment. During hysteroscopy biopsy can be taken from suspected area with precision and endometrial polyp can also be removed at the same time. Hysteroscopy is $100 \%$ accurate for intrauterine pathologies like polyp and submucous fibroid. Thus, Hysteroscopy is an important tool in the evaluation of patients with abnormal uterine bleeding and can be considered a gold standard for diagnosis of intrauterine pathologies and it should be included in management of patients with AUB.

\section{ACKNOWLEDGMENTS}

The author wants to show heartfelt gratitude to all his patients without whose co-operation, the study would not have been possible.

Funding: No funding sources Conflict of interest: None declared

Ethical approval: The study was approved by the Institutional Ethics Committee 


\section{REFERENCES}

1. Cohen MR, Paul W. Modern hysteroscopy: Diagnostic and therapeutic potential. Fertil Steril 1973:12;905-11.

2. Taneja SP. Hysteroscopy: Past, present and future. Med J Armed Force India. 2002;58:293-4.

3. Haemila FA, Youssef D, Hassan M, Soliman A, Mossad M. A prospective comparative study of 3-D ultrasonography and hysteroscopy in detecting uterine lesions in premenopausal bleeding. Middle East Fert Soc J. 2005; 10:238-43.

4. Varadarajan R, Sujatha M, Sreekantha. Role of hysteroscopy in abnormal uterine bleeding in perimenopausal age group. J Evol Med Dent Sci. 2013;2:114-8.

5. Jyotsana, Kamlesh M, Sudha S. Role of Hysteroscopy in evaluation of abnormal uterine bleeding. JK Sci. 2004;6(1):23-7.
6. Dasgupta S, Chakraborty B, Karim R1, Aich RK, Mitra P, Ghosh T. Abnormal uterine bleeding in perimenopausal age: diagnostic option and accuracy. J Obst Gyn India. 2011;61(2):189-94.

7. Michelle F, Archana B. Evaluation and histopathological correlation of abnormal uterine bleeding in perimenopausal women. Bombay Hospital J. 2010;52(1):69-72.

8. Sheetal GP, Bhute SB, Inamdar SA, Acharya NS, Srivastava DS. Role of diagnostic hysteroscopy in abnormal uterine bleeding and its histopathologic correlation. J Gynaecol Endo Surg. 2009;1(2):98104.

9. Pietro L, Merlin F, Saccardi C, Pozzan C, Sacco G, Fracas M. Role of hysteroscopy with endometrial biopsy to rule out endometrial cancer in postmenopausal women with abnormal uterine bleeding. Maturitas. 2005;50(2):117-23.

Cite this article as: Kaur G, Agarwal P. Role of hysteroscopy in management of abnormal uterine bleeding in perimenopausal women. Int J Reprod Contracept Obstet Gynecol 2016;5:1690-4. 